\title{
THE EFFECT OF MACHINING CONDITIONS ON THE FORCES IN THE PROCESS OF ROLLER BRUSH MACHINING
}

\author{
Jakub Matuszak' \\ 1 Department of Production Engineering, Mechanical Engineering Faculty, Lublin University of Technology, \\ 36 Nadbystrzycka Street, 20-618 Lublin, Poland, e-mail: j.matuszak@pollub.pl
}

Received: 2017.10 .25

Accepted: 2017.11.13

Published: 2017.12.05

\begin{abstract}
Because of its advantages, brushing processing has many uses. The main ones include the removal of corrosion products, surface cleaning, deburring and shaping the properties of the surface layer. The intensity of these processes depends on the degree of impact of brush fibres on the work surface. In the case of tools, in which the resilient fibres are the working elements, forces in the brushing process, apart from the machining parameters, depend on the characteristics and overall dimensions of individual fibres. The paper presents the results of studies of the influence of technological parameters and type of fibres on the radial force in the brushing process.
\end{abstract}

Keywords: brushing, machining conditions, radial force, cutting force.

\section{INTRODUCTION}

Brushing is one of the mechanical processing methods of the surface, which involves the effect of a rotating tool on the workpiece. There are many design solutions for brushes, and the basic division is related to the arrangement of working elements and divides the processing into cylindrical and front brush. The more detailed division concerns the materials used to fill brushes, which can be natural, artificial, composite in a form of sunken abrasive grains into plastic fibers. In addition, individual fibers can be found in a simple, crimped or knot form. Brushes with knot fibers are more rigid and are thus used for more aggressive applications. Fibers can also be characterized by chemical and temperature resistance.

By analysing the brushing process and the effects obtained after this treatment, it is difficult to clearly identify this process into a particular surface treatment method. At the intersection of the cylindrical surface of the fibre with the front one, an edge is formed, which can be treated as the cutting edge of the tool, which is present in typical machining tools. While brushing, the ma- terial removal nature of this process can be seen, however, the brushing products are comparable to those produced in abrasive processing. In turn, taking into account the kinematics of the treatment, individual fibres, while hitting the surface, perform the burnishing task analogous to the dynamic burnishing process $[13,14]$. The study results of the hardening of the surface layer and its favourable properties are presented in [2]. The study results on the increase of fatigue strength due to the favourable effect of brushing on the state of stresses and the hardening of the surface layer were presented. Considering various ways of impact of the brushing process on the surface and the surface layer, the brushing treatment can be treated as one of the hybrid processing methods. In practice, brushing is used to change the topography of the surface, remove corrosion products, paint coatings. The change of topography of the surface may be related to the decorative aspect or it may affect the surface development, the increase of free surface energy, which is of key importance in adhesion material bonding [4]. However, the most beneficial effects can be obtained by using the brush-cleaning treatment to 
remove undesirable burrs resulting from the milling, etc., or the changes in the condition of the edges of the objects in a form of rounding, chamfering, blunting $[1,8,9,11]$. Taking into account the fact that most elements after machining have burrs, the application of brushes in the machining centres creates a possibility of processing involving the removal of burrs directly after machining without dismantling the parts from the area of the treatment machine.

Measurement of the forces in the machining process allows to obtain a series of process information. Force analysis can be a direct information on the tool wear. The paper [5] analysed, among others, the impact of the tool type and the cutting speed on the value of cutting forces and their amplitude in the process of face milling. It has been shown that for the tools with fewer blades and small rake angles and helical line tilt, a greater value of the cutting force amplitudes was observed, which has an adverse effect on the durability of both the tools and the working systems of the tools.

The analysis of cutting forces is particularly important when cutting hard-to-machine materials, especially under the high cutting speeds-HSC. The [3] paper authors showed that the values of cutting forces impact the chip deformation, temperature and deformation of the surface layer material in the cutting zone. The study was conducted in terms of cutting speed $\mathrm{v}_{\mathrm{c}}=400-1200 \mathrm{~m} / \mathrm{min}$ for variable rake angle of the tools.

The decrease in cutting forces along with the increase in cutting speed under high speed machining was also demonstrated during the simulation using artificial neural networks at work [6].

Cutting force studies are especially important during the processing of thin-walled elements. The paper [10] measured the forces and acceleration in order to determine stable areas of thinwalled elements. The increase in amplitude of the forces was the information about the occurrence of self-excited vibrations of the chatter type.

The above analysis of the cutting forces concerned the machining process with rigid tools, such as monolithic milling cutters, milling heads, etc. The machining process with tools with elastic work elements, such as cylindrical brush fibres, is very complex. The effect on cutting forces, apart from the processing parameters, also comes from the fibre type, its length, and size of fibre packing on the brush periphery, affecting the rigidity of the entire tool. The phenomenon of the forced fibre deformation and rigidity of cylindrical brushes was theoretically described in the paper [12]. The mathematical relationships were presented describing the forces occurring in the contact zone of the fibre with the flat surface of the workpiece, comparing the buckling of the fibres with the buckling phenomenon.

Due to the limited amount of information related to the force analysis in the brushing process, the author of this article has attempted to determine the effect of the brushing parameters and the type of fibre used to fill the brushes on forces in the brushing process.

\section{METHODOLOGY OF THE RESEARCH}

The research was carried out on a vertical machining centre HX712G equipped with Fanuc control. The cylindrical crimped wire brushes were used for the research, whose features can be found in Table 1. The variation of structural features of the tools used consisted of using materials used on the fibres and different diameters of individual fibres, which resulted in the variable rigidity of the brushes used in the studies. The $15-5 \mathrm{PH}$ steel samples were used as a machining material, with the $100 \times 15 \times 5 \mathrm{~mm}$ dimensions.

The studies were performed using variable brushing speeds $\mathrm{v}_{\mathrm{c}}$ and variable feed rates $\mathrm{v}_{\mathrm{f}}$. The set of the technological parameters for brushing process is presented in Table 2. The constant feed-in value of $3 \mathrm{~mm}$ was used for all sets of parameters. Concurrent brushing was used without the application of machining liquids.

The research was carried out using the original force gauge. The load cell with the NA1 symbol was used, which allows for measurements of forces up to approx. $400 \mathrm{~N}$. The role of the load cell amplifier is played by a 24-bit analoguedigital converter with the sampling rate of approx. $100 \mathrm{~Hz}$. The digital signal is received by the microcontroller AVR - ATmega328 and by the COM port transmitted directly to the Microsoft Excel worksheet. Prior to the test, the device was featured within the permissible loads of the load cell, introducing a mathematical equation to the microcontroller converting the signal from the load cell to the force value. The research of the effect of brushing conditions on the forces was repeated five times. 
Table 1. Features and view of the brushes

\begin{tabular}{|l|c|c|c|}
\hline Symbol of the brush & M02 & S02 & S03 \\
\hline Fiber material & brass & steel & 0,3 \\
\hline Fiber diameter $(\mathrm{mm})$ & 0,2 & 0,2 & 120 \\
\hline Brush diameter $(\mathrm{mm})$ & \multicolumn{2}{|c|}{35} \\
\hline Fibers working length $(\mathrm{mm})$ & \multicolumn{2}{|c|}{} \\
\hline
\end{tabular}

Table 2. Sets of technological parameters of brushing process

\begin{tabular}{|c|c|c|c|c|c|c|c|c|c|}
\hline \multirow{3}{*}{$\begin{array}{l}\text { Brushing } \\
\text { parameters }\end{array}$} & Brushing speed $v_{c}(\mathrm{~m} / \mathrm{min})$ & 377 & 754 & 1131 & 1508 & \multicolumn{4}{|c|}{1131} \\
\hline & Feed rate $v_{f}(\mathrm{~mm} / \mathrm{min})$ & \multicolumn{4}{|c|}{370} & 140 & 370 & 1000 & 3700 \\
\hline & Feed-in (mm) & \multicolumn{8}{|c|}{3} \\
\hline
\end{tabular}

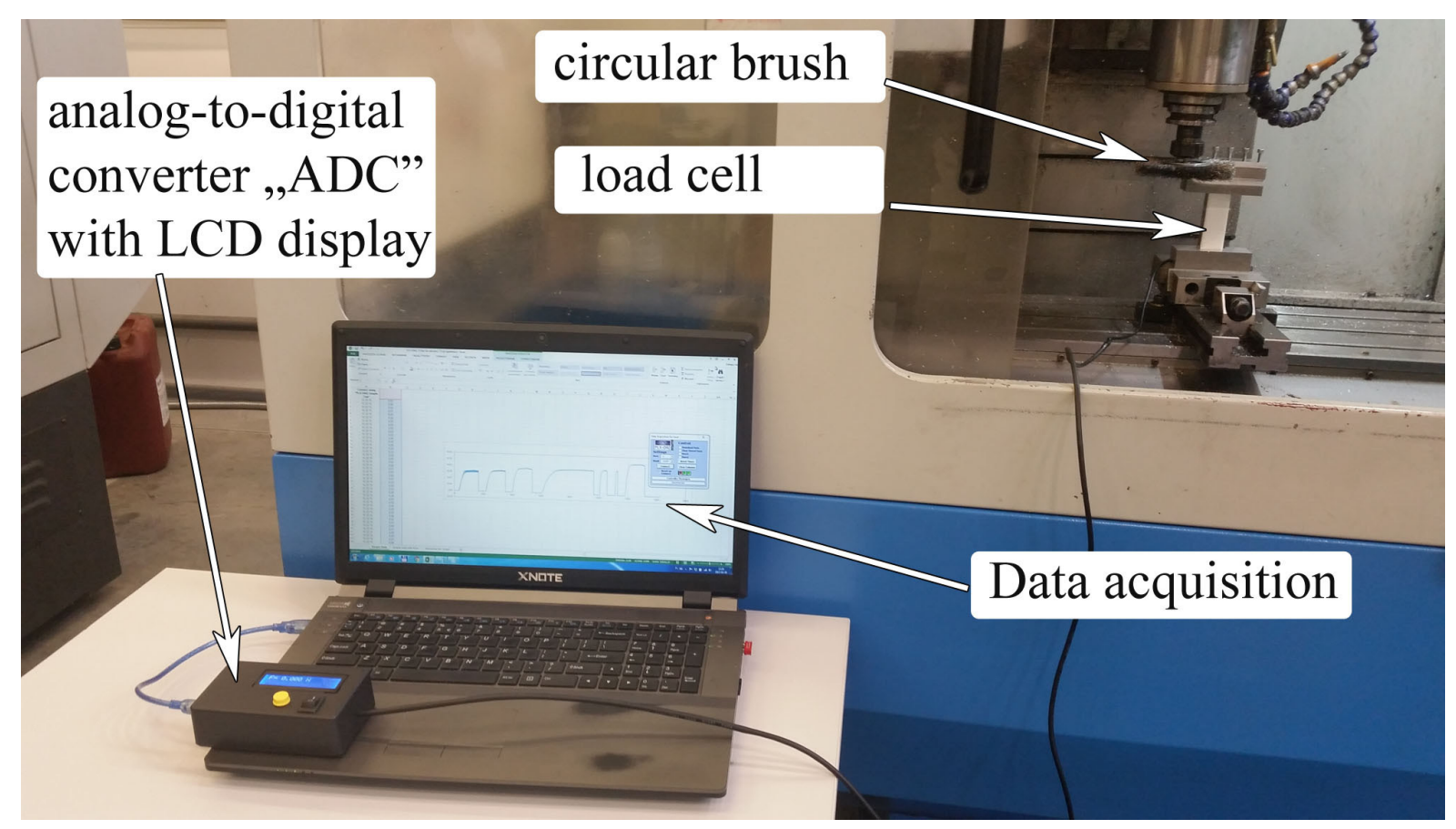

Fig. 1. View of test stand

\section{RESULTS OF THE RESEARCH}

Figure 2 presents the effect of brushing speed $\mathrm{v}_{\mathrm{c}}$ on the radial force in the brushing process for the applied brush types. For S02 and S03 brushes, as the brushing speed increased, the radial force got increased. In the case of M02 brush, until the speed value of $1131 \mathrm{~m} / \mathrm{min}$, the radial force increase was observed with the increase of the speed. While for the $1508 \mathrm{~m} / \mathrm{min}$ speed a reversed tendency can be observed - the force decrease due to the speed increase $\mathrm{v}_{\mathrm{c}}$.

The M02 brush has the most flexible fibres. At a speed of $1508 \mathrm{~m} / \mathrm{min}$, the brush revolves at speed about $66 \mathrm{rev} / \mathrm{s}$. The striking of the fibres into the work surface causes the fibres to bend, 


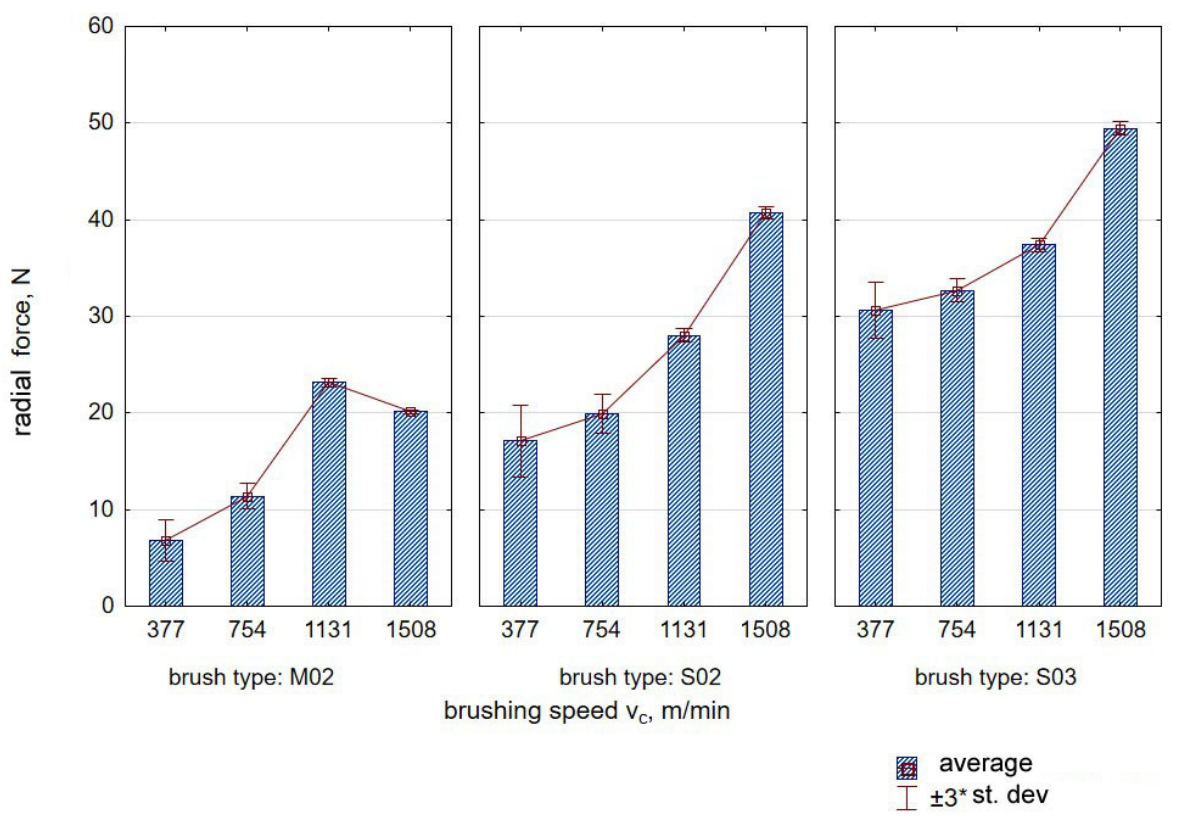

Fig. 2. The influence of brushing speed $v_{c}$ on the radial force value

which are unable to return to their original shape before the next entry into the workpiece contact zone. This results in a seemingly reduced dynamic brush diameter, and thus a reduction in the actual feed-in resulting in a decrease in the radial force. The phenomenon of determining the dynamic diameter of cylindrical brushes is described in [7].

Figure 3 presents the effect of the feed rate on the radial force for the brushes applied in the study. The increase of the radial force was observed along with the increase in the rigidity of the fibres. On the other hand, no significant effect of the feed rate on the radial force was observed. A bigger influence of the feed rate on the tangential force can be expected, however, this was not the subject of this study.

Figure 4 shows the effect of brushing speed on the amplitude of the radial force. For all tools a similar tendency was observed. The force amplitude decreased along with the increase of the brushing speed. The highest amplitude of the radial force, of about $4 \mathrm{~N}$, was achieved by brushing with a steel fibre tool with a diameter of $0,3 \mathrm{~mm}$ of individual fibres with the speed of $377 \mathrm{~m} / \mathrm{min}$. In turn, a stable course with a slight force amplitude was observed for the M02 brush while brushing with a speed of $1508 \mathrm{~m} / \mathrm{min}$. For a lower brushing speed, the number of individual fibre hits onto the treated surface in the time unit is smaller, which causes the amplitude to increase. This can be explained in the same way as machining with fewer blades, where the intermittent nature of the work is manifested by a greater amplitude, as shown in [5].

Similarly, for brushing, longer breaks between the strikes of individual fibres result in a temporary decrease in force relative to the maximum values in the working transition of the tool with the specified technological parameters, resulting in the observed increase of amplitude. On the other hand, the increase in brushing speed causes an increase in the number of strikes of individual fibres and somewhat "flattening" the course of the force - reducing the amplitude, which can be observed in the graphs of the radial force courses presented in Figure 5.

Figure 6 presents the impact of the feed rate $v_{f}$ on the amplitude of the radial force.

For M02 brush, the amplitude value compared to S02 and S03 brushes are smaller, however, this is due to smaller forces, which were obtained for this tool. While no influence of the feed rate was observed on the amplitude value of the radial force for the studied brushes.

\section{CONCLUSIONS}

The paper presents the research results of the influence of technological parameters and the type of fibre of the cylindrical brushes on the values and course of the radial force. The following conclusions sum up the conducted experimental research: 


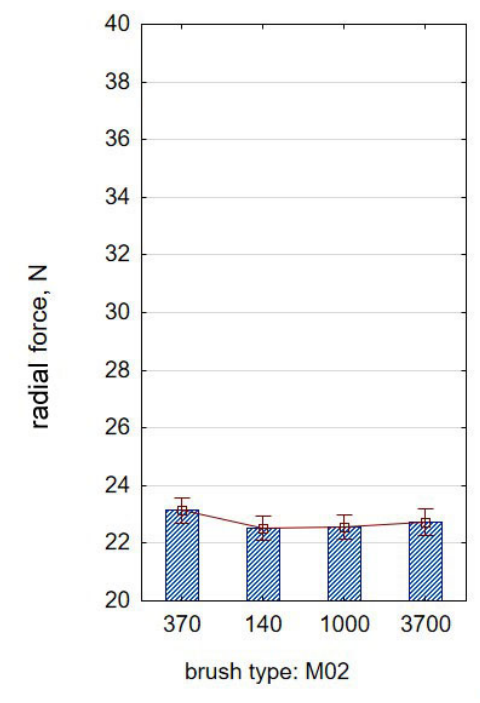

feed rate $\mathrm{v}_{\mathrm{f}}, \mathrm{mm} / \mathrm{min}$

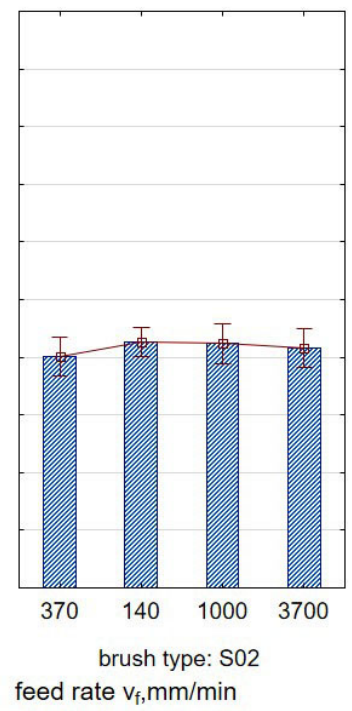

average
$\pm 3^{*}$ st. dev.

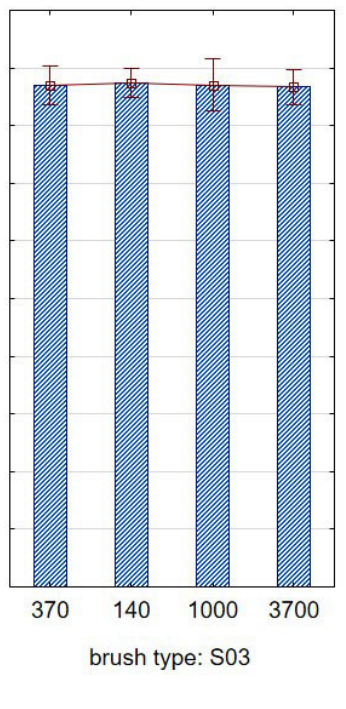

Fig. 3. The influence of feed rate on the radial force value

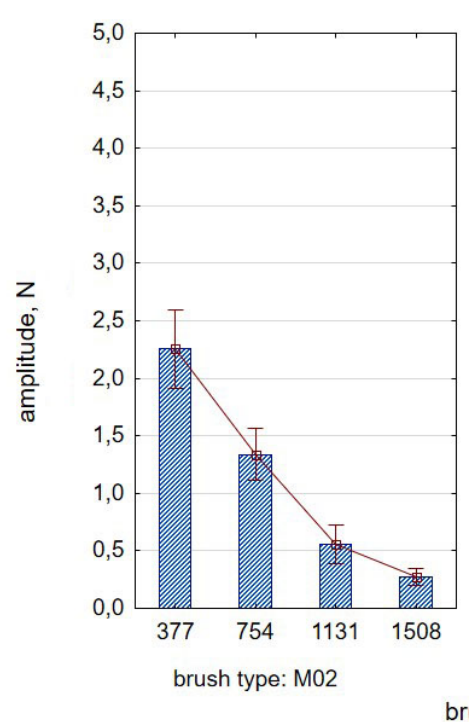

brushing speed $\mathrm{v}_{\mathrm{c}}, \mathrm{m} / \mathrm{min}$

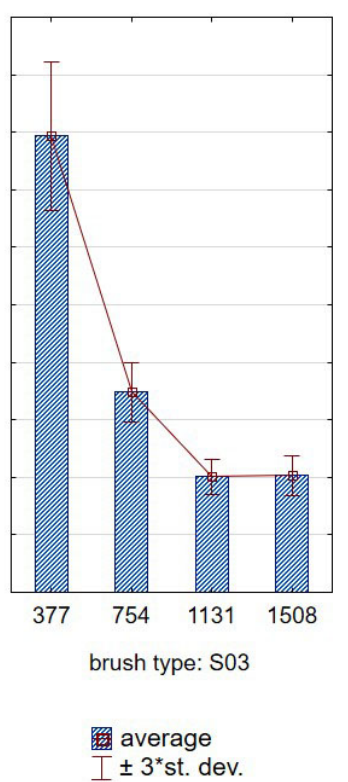

Fig. 4. The influence of brushing speed $v_{c}$ on the amplitude value of the radial force

- For S02 and S03 tools, the radial force increases in the entire studied scope along with the increase of the brushing speed

- During machining with the M02 tool, until the $\mathrm{v}_{\mathrm{c}}=1131 \mathrm{~m} / \mathrm{min}$ speed, the radial force increase is observed along with the speed increase, while the radial force decrease was noted for the greatest brushing speed used in the studies $\mathrm{v}_{\mathrm{c}}=1508 \mathrm{~m} / \mathrm{min}$ compared to the speed of $\mathrm{v}_{\mathrm{c}}=1131 \mathrm{~m} / \mathrm{min}$, which is due to the reduction of the dynamic diameter of the rotat- ing tool with the most flexible filaments from the examined tools

- No significant impact of the feed rate was observed on the value of the radial force.

- The force amplitude decreases along with the increase in the brushing speed.

Brushing is often used in the deburring process. The performed studies of the impact of technological parameters of brushing on the course of the radial force can be particularly useful in 


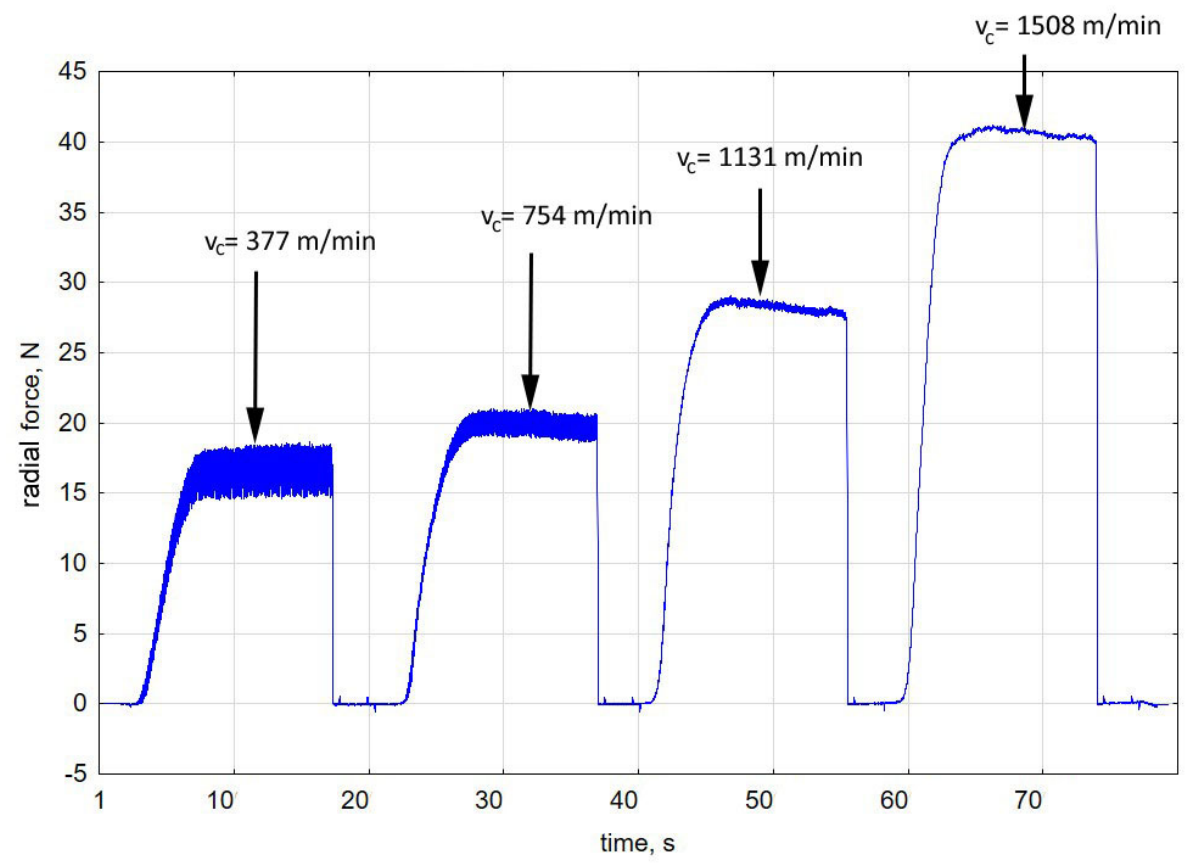

Fig. 5. The course of the radial force in the time function for the variable brushing speeds $v_{c}$

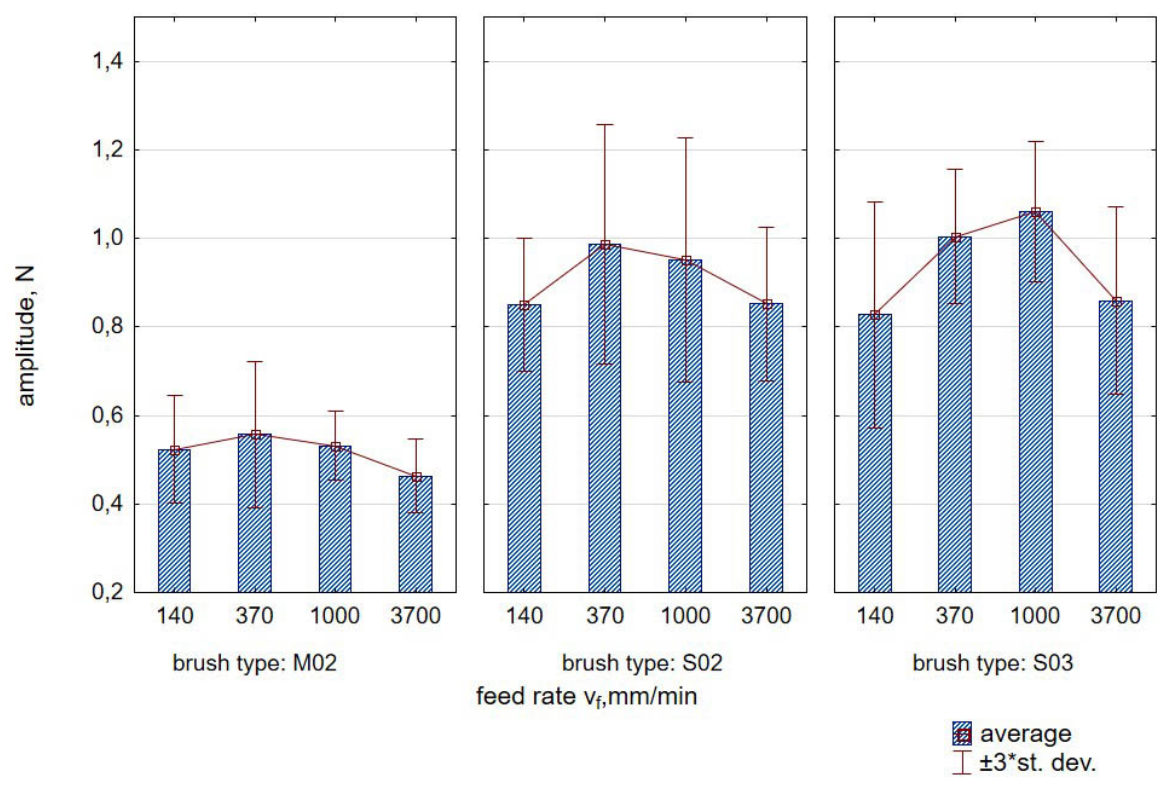

Fig. 6. The impact of feed rate on the amplitude value of the radial force

the machining of thin-walled elements with the reduced rigidity. Due to the availability of various types of structural solutions of the brushes (various brush diameters, fibre diameters, working lengths of fibres and materials of which they are made), it is possible to select a tool so that the force needed to remove the burrs is relatively high, while the relation of the amplitude to the force value is relatively low in order to reduce the vibrations of elements with the reduced rigidity. Furthermore, it can be noted that the forces, and to a greater extent the force amplitudes in the brushing process, are significantly lower compared to milling.

\section{REFERENCES}

1. Aurich J.C., Dornfeld D., Arrazola P.J., Franke V. Leitz L., Min S.: Burrs-Analysis, control and removal. CIRP Annals - Manufacturing Technology. 58, 2, 2009, 519-542. 
2. Fredj N.B., Nasr M.B., Rhouma A.B., Sidhom H., Braham C.: Fatigue life improvements of the AISI 304 stainless steel ground surfaces by wire brushing. J. of Materi Eng and Perform. 13, 5, 2004, 564-574.

3. Gziut O., Kuczmaszewski J., Zagórski I.: The influence of technological parameters and geometric features of a cutting edge on cutting forces during AZ91HP alloy milling. Advances in Manufacturing Science and Technology. Vol. 38, nr 2, 2014.

4. Kłonica M., Kuczmaszewski, J.: Determining the value of surface free energy on the basis of the contact angle. Adv. Sci. Technol. Res. J. 11, 1, 2017, 66-74.

5. Kuczmaszewski J., Pieśko P.: Wear of milling cutters resulting from high silicon aluminium alloy cast AlSi21CuNi machining. Eksploatacja i Niezawodnosc. Vol. 16, no. 1, 2014.

6. Kulisz M., Zagórski I., Semeniuk A.: Artificial neural network modelling of cutting force components during AZ91HP alloy milling. Applied Computer Science. 12, 4, 2016.

7. Matuszak J., Zaleski K.: Dynamic Diameter Determination of Circular Brushes. Applied Mechanics and Materials. 791, 2015, 232-237.

8. Matuszak J., Zaleski K.: Edge states after wire brushing of magnesium alloys. Aircraft Eng \& Aerospace Tech. 86, 4, 2014, 328-335.

9. Overholser R.W., Stango R.J., Fournelle R.A.: Morphology of metal surface generated by nylon/abrasive filament brush. International Journal of Machine Tools and Manufacture. 43, 2, 2003, 193-202.

10. Rusinek R., Zaleski K.: Dynamics of thin-walled element milling expressed by recurrence analysis. Meccanica. 51, 6, 2016, 1275-1286.

11. Stango R.J.: Filamentary brushing tools for surface finishing applications. Metal Finishing. 100, 2002, 82-91.

12. Stango R.J., Heinrich S.M., Shia C.Y.: Analysis of Constrained Filament Deformation and Stiffness Properties of Brushes. J. Eng. Ind. 111, 3, 1989, 238-243.

13. Zaleski K.: The effect of vibratory and rotational shot peening and wear on fatigue life of steel. Eksploatacja i Niezawodnosc - Maintenance and Reliability. 19, 1, 2016, 102-107.

14. Zaleski R., Zaleski K., Gorgol M., Wiertel M.: Positron annihilation study of aluminum, titanium, and iron alloys surface after shot peening. Appl. Phys. A. 120, 2, 2015, 551-559. 